\title{
PEMANFAATAN SERBUK TEMPURUNG KELAPA PADA KOMPOSIT $\mathrm{Al}_{2} \mathrm{O}_{3}$-EPOXY
}

\author{
Ahmad Syafruddin Zohri ${ }^{1}$, Nasmi Herlina Sari ${ }^{2}$, Sujita ${ }^{3}$ \\ Jurusan Teknik Mesin, Fakultas Teknik, Universitas Mataram \\ Email : syafruddinzohri@gmail.com
}

\begin{abstract}
Abstrak
Tujuan dari penelitian ini adalah pemanfaatan serbuk tempurung kelapa pada komposit $\mathrm{Al}_{2} \mathrm{O}_{3}$-Epoxy sehingga dapat dijadikan sebagai bahan alternatif pengganti material gesek kampas rem yang ramah lingkungan. Pada penelitian ini, serbuk tempurung kelapa dimanfaatkan sebagai bahan pengisi pada komposit $\mathrm{Al}_{2} \mathrm{O}_{3}$-Epoxy yang dibuat dengan menggunakan metode hand lay up. Perbandingan fraksi volume serbuk tempurung kelapa dan $\mathrm{Al}_{2} \mathrm{O}_{3}$ divariasikan sebesar 0:40, 10:30, 20:20, 30:10 dan 40:10 (\%). Perekat yang digunakan adalah resin epoxy yaitu sebesar $60 \%$. Pengujian yang dilakukan adalah pengujian keausan. Hasil penelitian menunjukkan bahwa pemanfaatan serbuk tempurung kelapa pada komposit $\mathrm{Al}_{2} \mathrm{O}_{3}$-Epoxy dapat menurunkan nilai keausan sehingga dapat dijadikan sebagai bahan alternatif penggati material gesek kampas rem yang ramah lingkungan.
\end{abstract}

The purpose of this research is utilization of coconut shell powder on Al2O3-Epoxy composite so it can be used as an alternative material of brake linings that are enviromentlly friendly. In this research, coconut shell powder is used as a filler on $\mathrm{Al}_{2} \mathrm{O}_{3}$-Epoxy composites that are made using hand lay up method. Comparison volume fraction of coconut shell powder and $\mathrm{Al}_{2} \mathrm{O}_{3}$ was varied amount 0:40, 10:30, 20:20, 30:10 and 40:0 (\%). Adhesive was used is epoxy resin namely amount $60 \%$. Test conducted is wear test. The results showed that utilization of coconut shell powder on $\mathrm{Al}_{2} \mathrm{O}_{3}$-Epoxy can be decrease the wear so it can be used as an alternative material of brake linings that are environmentally friendly

Key words : composites, coconut shell powder, $\mathrm{Al}_{2} \mathrm{O}_{3}$, epoxy, wear test.

\section{PENDAHULUAN}

Kampas rem merupakan salah satu komponen kendaraan yang memiliki peranan penting dalam keselamatan berkendara. Kampas rem berdasarkan bahan penyusun material geseknya dibagi menjadi tiga yaitu kampas rem asbestos, kampas rem semimetalic dan kampas rem free-asbestos. Dari ketiga jenis kampas rem tersebut, kampas rem non-asbestos adalah jenis kampas rem yang paling ramah lingkungan dan memiliki performa gesek yang tidak kalah dari jenis kampas rem asbestos dan semimetalic. Kampas rem non-asbestos menggunakan bahan - bahan organic sebagai unsur penyusun material geseknya. Tempurung kelapa merupakan salah satu bahan organic yang dapat dijadikan sebagai bahan penyusun material gesek kampas rem karena memiliki kekerasan dan kerapatan tinggi serta serapan yang air yang rendah sehingga akan mempunyai koefisien gesek yang baik. Tujuan dari penelitian ini adalah pemanfaatan serbuk tempurung kelapa pada komposit $\mathrm{Al}_{2} \mathrm{O}_{3}$-Epoxy sehingga dapat dijadikan sebagai bahan alternatif pengganti material gesek kampas rem yang ramah lingkungan.

\section{LANDASAN TEORI \\ Material gesek kampas rem}

Masing - masing tipe sepeda motor memiliki bentuk serta kualitas bahan kampas rem yang berbeda - beda. Pada aplikasi sistem pengereman otomotif yang aman dan efektif, bahan friksi harus memenuhi persyaratan minimum mengenai unjuk kerja dan daya tahannya. Bahan rem harus memenuhi persyaratan keamanan, ketahanan dan dapat mengerem dengan halus. Selain itu juga harus mempunyai koefisien gesek yang tinggi, keausan kecil, kuat, tidak melukai permukaan roda dan dapat menyerap getaran. Salah satu karakterisasi yang perlu dilakukan dalam pembuatan material gesek kampas rem sepeda motor adalah karakterisai keausan. Nilai rata - rata keausan yang harus dimiliki material gesek kampas rem adalah $5 \times 10^{-4}$ $-5 \times 10^{-3} \mathrm{~mm}^{2} / \mathrm{kg}$ (Hutchings, 1992). 


\section{Material komposit}

Kata komposit memberikan suatu pengertian yang sangat luas dan berbeda beda mengikuti situasi dan perkembangan bahan itu sendiri. Gabungan dua atau lebih bahan merupakan suatu konsep yang diperkenalkan untuk menerangkan definisi komposit (Sari, 2009).

Komposit dibentuk dari dua jenis material utama yaitu penguat (reinforcement) dan matriks sebagai pengikat. Keunggulan dari material komposit bila dibandingkan dengan material lainnya adalah penggabungan unsur - unsur pembentuknya tersebut. Sifat material hasil penggabungan ini diharapkan dapat saling melengkapi kelemahan-kelemahan yang ada pada masing-masing material penyusunnya. Dengan memilih kombinasi material penguat dan pengikat yang tepat, maka dapat dihasilkan suatu material komposit dengan sifat yang sesuai dengan keinginan. Material komposit memiliki beberapa keunggulan diantaranya bobot ringan, mempunyai kekuatan dan kekakuan yang baik, biaya produksi yang murah, tahan korosi dan lain - lain.

\section{Tempurung kelapa}

Tanaman kelapa dikenal sebagai pohon yang mempunyai banyak kegunaan, mulai dari akar sampai pada ujungnya (daun). Tinggi pohon kelapa dapat mencapai 15 sampai 30 meter di daerah perkebunan. Buah kelapa berbentuk lonjong dan dilapisi oleh kulit yang licin yang berwarna hijau terang, jingga cerah atau warna - warna gading. Di bawah lapisan kulit terdapat lapisan serat tebal yang digunakan untuk sabut. Lapisan berikutnya adalah tempurung. Tempurung dapat digunakan untuk membuat arang dan alat alat makan.

Berat dan tebal tempurung kelapa sangat ditentukan oleh jenis tanaman kelapa. Tempurung kelapa beratnya sekitar 15 - $19 \%$ bobot buah kelapa dengan ketebalan 3 - $5 \mathrm{~mm}$. Komposisi kimia tempurung kelapa terdiri atas selulosa $(26,60 \%)$, pentosan $(27,70 \%)$, lignin $(29,40$ $\%)$, abu $(0,60 \%)$, solvent ekstraktif $(4,20$ $\%)$, uronat anhidrat $(3,50 \%)$, nitrogen $(0,11$ $\%)$ dan air 8,00 \%) (Rusdianto, 2011).

\section{Aluminium Oksida $\left(\mathrm{Al}_{2} \mathrm{O}_{3}\right)$}

Aluminium oksida adalah sebuah senyawa kimia dari aluminium dan oksigen, dengan rumus kimia $\mathrm{Al}_{2} \mathrm{O}_{3}$. Aluminium oksida memiliki kekerasan 9 dalam skala Mohs. Hal ini menyebabkannya banyak digunakan sebagai abrasif untuk menggantikan intan yang jauh lebih mahal.

Alumina mempunyai morfologi sebagai bubuk bewarna putih dengan berat molekul 102, titik leleh leleh pada $2070{ }^{\circ} \mathrm{C}$ dan spesifikasi gravity $3,5-4,0$. Sifat fisis yang dimiliki keramik $\mathrm{Al}_{2} \mathrm{O}_{3}$ antara lain adalah densitas sebesar $3960 \mathrm{~kg} / \mathrm{m}^{3}$, nilai kekerasan antara $1500-1800 \mathrm{kgf} / \mathrm{mm}^{2}$ dan kuat tekan berkisar antara $230-350 \mathrm{MPa}$ (Gernot, 1989).

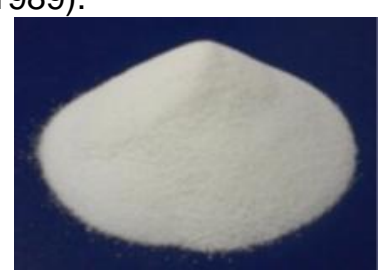

Gambar 1 Aluminium Oksida $\left(\mathrm{Al}_{2} \mathrm{O}_{3}\right)$.

\section{Perekat epoxy}

Perekat ini merupakan produk sintetik termoset dari reaksi resin poliepoxy dengan zat pengeras yang dapat diperoleh dalam bentuk sistem satu atau dua komponen. Sistem satu komponen meliputi resin cair bebas pelarut, larutan, pasta cair, bubuk, pellet dan pasta. Sistem dua komponen terdiri dari resin cair dan zat curing yang digunakan dengan cara dicampur.

Epoxy resin memiliki berbagai keunggulan sebagai zat perekat dibandingkan dengan polimer - polimer yang lain diantaranya adalah keaktifan permukaan yang tinggi, daya pembasahan baik, kekuatan kohesif yang tinggi, tidak mengkerut, dapat luwes diubah - ubah sifatnya dengan memilih resin-hardener yang tepat. Perekat epoxy kekuatannya tidak berubah dalam waktu lama, tahan minyak, gemuk, panas atau cauca dingin (Hartomo, 1992).

\section{Pengujian Keausan}

Secara definisi, keausan adalah hilangnya sejumlah lapisan permukaan material karena adanya gesekan antara permukaan padatan dengan benda lain (Prasetyo, 2012). Pengujian keausan dapat dilakukan dengan berbagai macam metode dan teknik, yang semuanya bertujuan untuk mensimulasikan kondisi keausan aktual. Laju keausan dapat dinyatakan dengan : 


$$
\begin{aligned}
\mathrm{W} & =\frac{V_{0}-V_{1}}{L \times P} \\
\mathrm{~L} & =2 \cdot \pi \cdot \mathrm{R} \cdot \mathrm{N} \\
\mathrm{N} & =\mathrm{n} \cdot \mathrm{t}
\end{aligned}
$$

dimana :

$\mathrm{W}=$ Nilai keausan $\left(\mathrm{mm}^{2} / \mathrm{kg}\right)$.

$V_{0}=$ Volume awal spesimen $\left(\mathrm{mm}^{3}\right)$.

$V_{1}=$ Volume akhir spesimen $\left(\mathrm{mm}^{3}\right)$.

$L \quad=$ Panjang lintasan $(\mathrm{mm})$.

$\mathrm{R}=$ Jarak pusat piringan pengaus $\mathrm{ke}$ pusat spesimen (mm).

$P=$ Besar pembebanan $(\mathrm{kg})$.

$\mathrm{N}=$ Jumlah putaran piringan pengaus.

$\mathrm{n}=$ Kecepatan putaran piringan pengaus (rpm).

$\mathrm{t} \quad=$ Lama putaran piringan pengaus (menit).

\section{METODE PENELITIAN}

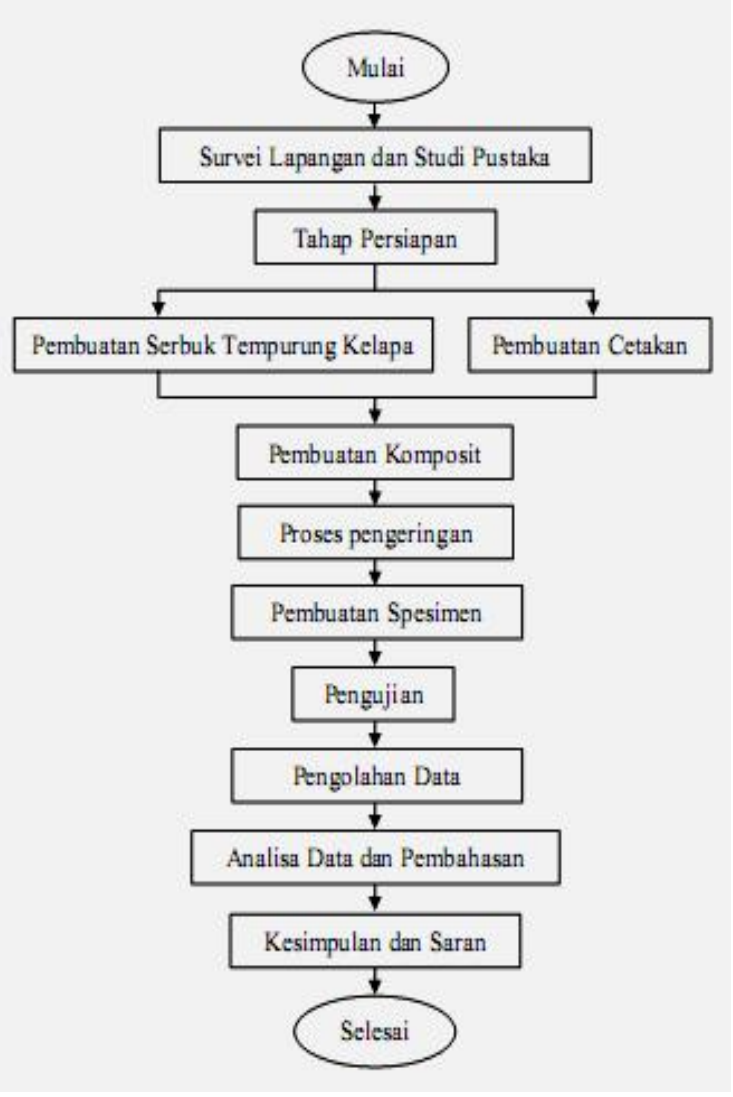

Gambar 2 Diagram alir penelitian.

\section{Pembuatan serbuk tempurung kelapa}

Berikut ini adalah langkah-langkah proses pembuatan serbuk tempurung kelapa: a. Memilih tempurung kelapa yang sudah tua.

b. Tempurung kelapa dibersihkan dari sisa-sisa serabut kelapa yang masih menempel dengan cara diamplas.

c. Tempurung kelapa dijemur selama satu hari untuk mengurangi kandungan air didalamnya.

d. Tempurung kelapa dijadikan serbuk dengan cara digerinda.

e. Serbuk yang didapatkan kemudian diayak dengan ayakan 80 mesh.

f. Serbuk tempurung kelapa siap digunakan sebagai bahan penguat komposit alternatif pengganti material gesek kampas rem.

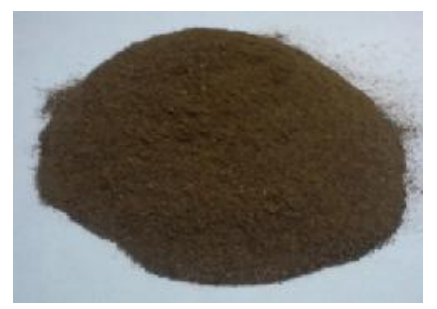

Gambar 3 Serbuk Tempurung Kelapa.

\section{Pembuatan cetakan}

Cetakan dibuat dengan bentuk dan ukuran yang disesuaikan dengan spesimen yang akan dibuat yaitu dengan menggunakan pipa aluminium dengan diameter $10,5 \mathrm{~mm}$ dan panjang $22 \mathrm{~mm}$.

\section{Pembuatan specimen}

Berikut adalah langkah - langkah proses pembuatan spesimen pengujian :

a. Mempersiapkan alat dan bahan yang dibutuhkan.

b. Pengolesan wax mold release pada cetakan untuk mempermudah proses pelepasan spesimen dari cetakan.

c. Tuangkan serbuk tempurung kelapa ke dalam gelas pencampur sesuai komposisi yang telah ditentukan.

d. Tuangkan $\mathrm{Al}_{2} \mathrm{O}_{3}$ ke dalam gelas pencampur sesuai komposisi yang telah ditentukan.

e. Tuangkan resin epoxy ke dalam gelas pencampur yang telah berisi serbuk tempung kelapa dan $\mathrm{Al}_{2} \mathrm{O}_{3}$ dan kemudian diaduk hingga benar - benar merata.

f. Tuangkan hasil campuran serbuk tempurung kelapa, $\mathrm{Al}_{2} \mathrm{O}_{3}$ dan resin epoxy ke dalam cetakan yang telah tersedia. 
g. Tutup cetakan dengan kaca dan diberikan penekanan sebesar $6,67 \times 10^{3} \mathrm{~Pa}$.

h. Setelah kering, angkat/keluarkan spesimen dari cetakan.

i. Terakhir adalah proses perataan dan penghalusan permukaan spesimen agar sesuai dengan bentuk yang telah ditentukan.

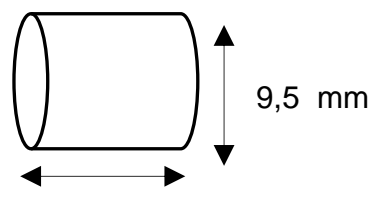

$20 \mathrm{~mm}$

Gambar 4 Dimensi spesimen pengujian keausan.

\section{Pengujian keausan}

Pengujian keausan dilakukan dengan menggunakan alat grinder polisher yang pada piringan pengausnya dilapisi amplas water proof dengan ukuran butir pengaus 1000 mesh dan diberikan penekanan sebesar $1 \mathrm{~kg}$.

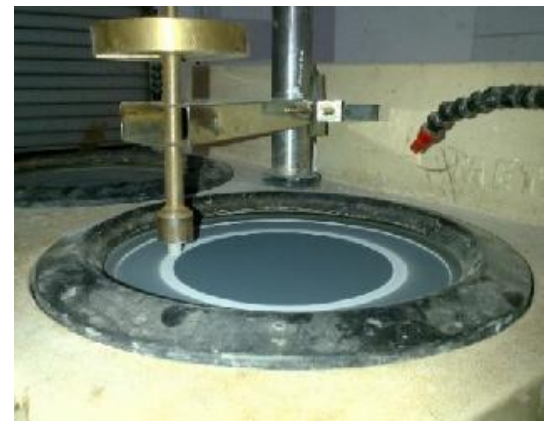

Gambar 5 Proses pengujian keausan.

HASIL DAN PEMBAHASAN

Tabel 1 Hasil Pengujian Keausan

\begin{tabular}{|cc|cc|c|}
\hline Fraksi Volume & \multicolumn{4}{c|}{ Silai Keausan $\left(\times 10^{-4} \mathrm{~mm}^{2} / \mathrm{kg}\right)$} \\
\cline { 2 - 5 } STK : Al $203(\%)$ & Spesimen I & Spesimen II & Spesimen III & Rata - Rata \\
\hline $0: 40$ & 1,3 & 1,09 & 1,12 & 1,17 \\
\hline $10: 30$ & 1,07 & 1,19 & 0,92 & 1,06 \\
\hline $20: 20$ & 0,8 & 0,52 & 0,65 & 0,66 \\
\hline $30: 10$ & 0,33 & 0,56 & 0,32 & 0,40 \\
\hline $40: 0$ & 0,67 & 0,59 & 0,62 & 0,66 \\
\hline
\end{tabular}

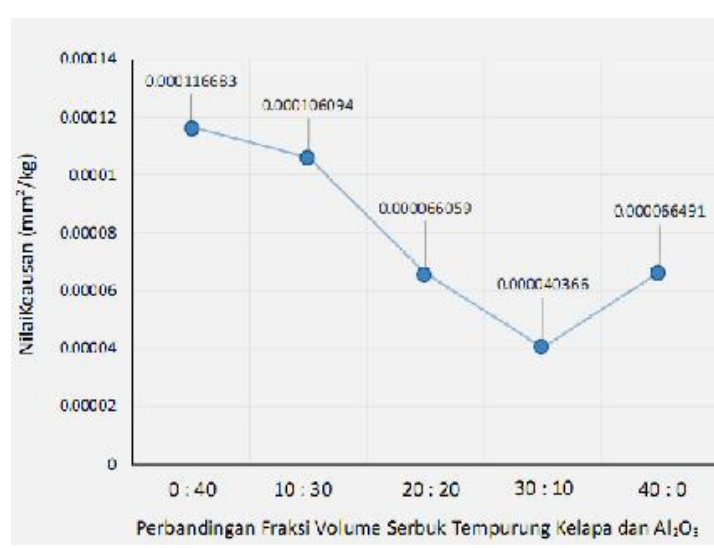

Gambar 6 Nilai Keausan Vs Perbandingan fraksi volume serbuk tempurung kelapa dan $\mathrm{Al}_{2} \mathrm{O}_{3}$.

Berdasarkan gambar 6 dapat dilihat bahwa nilai rata - rata keausan komposit menjadi semakin menurun seiring dengan penambahan persentase serbuk tempurung kelapa (STK). Pada penelitian ini digunakan lima variasi perbandingan fraksi volume serbuk tempurung kelapa dan $\mathrm{Al}_{2} \mathrm{O}_{3}$ yaitu 0:40, 10:30, 20:20, 30:10 dan 40:10 (\%).

Pada variasi perbandingan fraksi volume 0:40 (\%) didapatkan nilai keausan sebesar $1,17 \times 10^{-4} \mathrm{~mm}^{2} / \mathrm{kg}$ dimana nilai tersebut merupakan nilai keausan tertinggi yang didapatkan dari lima macam variasi yang diuji. Hal ini terjadi dikarenakan dimensi partikel $\mathrm{Al}_{2} \mathrm{O}_{3}$ yang relatif besar menyebabkan kekuatan komposit menjadi lemah sehingga nilai keausan yang didapat menjadi tinggi.

Pada variasi perbandingan fraksi volume 10:30 (\%) dan 20:20 (\%), nilai keausan menurun $9,4 \%$ dan $43,58 \%$ menjadi $1,06 \times 10^{-4} \mathrm{~mm}^{2} / \mathrm{kg}$ dan $0,66 \times 10^{-4}$ $\mathrm{mm}^{2} / \mathrm{kg}$. Dengan dimensi partikel serbuk tempurung kelapa yang lebih kecil dibandingkan dengan $\mathrm{Al}_{2} \mathrm{O}_{3}$ maka serbuk tempurung kelapa dapat mengisi kekosongan pada ikatan resin dan $\mathrm{Al}_{2} \mathrm{O}_{3}$ sehingga kekuatan komposit menjadi meningkat. Peningkatan kekuatan ini menyebabkan nilai keausan pada komposit menjadi menurun.

Demikian pula pada variasi perbandingan fraksi volume 30:10 (\%) yang nilai keausannya menurun $65,81 \%$ atau menjadi sebesar $0,4 \times 10^{-4} \mathrm{~mm}^{2} / \mathrm{kg}$ yang dimana nilai ini adalah nilai keausan terendah dari lima variasi yang diuji. Dominasi partikel serbuk tempurung kelapa 
yang mengandung karbon dengan dimensi yang relatif kecil mempengaruhi ikatan dan kekerasan yang didapat pada variasi ini. Kandungan karbon pada serbuk tempurung kelapa meningkatkan kekerasan sehingga menyebabkan penurunan nilai keausan.

Pada variasi perbandingan fraksi volume 40:0 (\%) nilai keausan mengalami sedikit peningkatan. Hal ini disebabkan karena jumlah partikel serbuk tempurung kelapa yang relatif banyak pada variasi ini sehingga resin tidak dapat menutupi seluruh permukaan tiap-tiap partikel serbuk tempurung kelapa yang menyebabkan kekuatan komposit menjadi menurun. Penurunan kekeuatan inilah yang menyebabkan peningkatan pada nilai keausan yang didapatkan.

Dari lima variasi perbandingan fraksi volume komposit yang telah diuji, hasil analisa data menunjukkan bahwa nilai keausan yang didapat berkisar antara 1,17 $\times 10^{-4}-0,40 \times 10^{-4} \mathrm{~mm}^{2} / \mathrm{kg}$. Nilai ini lebih

rendah apabila dibandingkan dengan nilai rata - rata keausan yang harus dimiliki material gesek kampas rem yaitu $5 \times 10^{-}$ ${ }^{4}-5 \times 10^{-3} \mathrm{~mm}^{2} / \mathrm{kg}$ (Hutchings, 1992). Hal ini menunjukkan bahwa nilai keausan komposit yang dibuat lebih baik dari nilai keausan rata-rata yang harus dimiliki kampas rem.

Berdasrkan hasil karakterisasi keausan yang telah dilakukan, diketahui bahwa pemanfaatan serbuk tempurung kelapa pada komposit $\mathrm{Al}_{2} \mathrm{O}_{3}$-Epoxy dapat meningkatkan sifat mekanik yang dihasilkan yaitu berupa penurunan nilai keausan sehingga komposit yang dibuat dapat dijadikan sebagai bahan alternatif pengganti material gesek kampas rem berdasarkan perkiraan nilai keausannya dengan keungulan komposit yang dimiliki yaitu ringan dan kuat.

\section{KESIMPULAN}

Pemanfaatan serbuk tempurung kelapa pada komposit $\mathrm{Al}_{2} \mathrm{O}_{3}$-Epoxy dapat menurunkan nilai keausan sehingga dapat dijadikan sebagai bahan alternatif penggati material gesek kampas rem yang ramah lingkungan berdasarkan nilai keausannya. Nilai keausan terendah didapat pada komposit dengan variasi perbandingan fraksi volume serbuk tempurung kelapa dengan $\mathrm{Al}_{2} \mathrm{O}_{3}$ sebesar $30: 10$ (\%) yaitu 0,40 $\times 10^{-4} \mathrm{~mm}^{2} / \mathrm{kg}$ dan yang tertinggi pada

variasi perbandingan fraksi volume serbuk tempurung kelapa dengan $\mathrm{Al}_{2} \mathrm{O}_{3}$ sebesar $0: 40(\%)$ yaitu $1,17 \times 10^{-4} \mathrm{~mm}^{2} / \mathrm{kg}$.

\section{DAFTAR PUSTAKA}

Gernot, K. 1989. High-Tech Ceramics. London. Academic Press.

Hartomo, A.J. 1992. Memahami Polimer dan Perekat. Yogyakarta. Andi Offset.

Hutchings, I. M. 1992. Tribology Friction and Wear of Engineering Materials. London. Hodder Headline PLC.

Prasetyo, A. B. 2012. Keausan. http://blog.ub.ac.id/agungbp09/.

Rusdianto, A. 2011. Pemanfaatan Serbuk Tempurung Kelapa Sebagai Campuran Gipsum Plafon Dengan Bahan Pengikat Lateks Akrilik. Tugas Akhir. Fakultas Matematika dan IImu Pengetahuan Alam Universitas Sumatra Utara.

Sari, N. H. 2009. Diktat Polymer and Composite. Jurusan Teknik Mesin Fakultas Teknik Universitas Mataram 